\title{
Effect of electromagnetic field on the solidification structure of C19400 copper alloy
}

\author{
Baomian $\mathrm{Li}^{\mathrm{a}}$, Haitao Zhang and Jianzhong Cui \\ Key Laboratory of Electromagnetic Processing of Materials, Ministry of Education, Northeastern University, \\ Shenyang, Liaoning, China
}

\begin{abstract}
The as-cast structure of $\mathrm{C} 19400$ copper alloy $(\mathrm{Cu}-2.32 \% \mathrm{Fe}-0.035 \% \mathrm{P}-0.11 \mathrm{Zn}$ in mass\%) under electromagnetic field had been researched in this paper. It is shown that applying electromagnetic field during the solidification of C19400 copper alloy can promote columnar-to-equiaxed transition, refine grain, eutactics and $\mathrm{Fe}_{2} \mathrm{P}$ phase. The morphology of $\mathrm{Fe}_{2} \mathrm{P}$ phase changes from coarse irregular shape to fine dotlike shape. The greater the current intensity, the more obvious the above-mentioned effects.
\end{abstract}

Keywords: C19400 copper alloy, electromagnetic field, solidification structure.

\section{Introduction}

Copper-base alloys with high strength and high electrical conductivity are widely used to make electronic components such as IC lead frames, connectors, pins, terminals, relays and switches. $\mathrm{Cu}-\mathrm{Cr}-\mathrm{Zr}$, $\mathrm{Cu}-\mathrm{Ni}-\mathrm{Si}$ and $\mathrm{Cu}-\mathrm{Fe}-\mathrm{P}$ system alloys are now the typical ones. However, $\mathrm{Cu}-\mathrm{Cr}-\mathrm{Zr}$ system alloys are difficult to smelt and cast under atmospheric conditions, and $\mathrm{Cu}-\mathrm{Ni}-\mathrm{Si}$ system alloys do not accommodate plating well. Therefore Cu-Fe-P system alloys, especially C19400 copper alloy $(\mathrm{Cu}-2.32 \% \mathrm{Fe}-0.035 \% \mathrm{P}-0.11 \mathrm{Zn}$ in mass $\%)$, are now the most widely used ones owing to their better overall properties and relatively low cost [1-4].

The slabs of C19400 copper alloy are generally produced by semi-continuous casting. During the semi-continuous casting process transverse surface cracks are often observed if secondary cooling is strong [5]. To prevent the formation of cracks, secondary cooling is usually weak in the actual production. Slow cooling rate associated with this method results in the coarse as-cast structure, which not only increases the difficulty of hot rolling but greatly deteriorates the overall performance of the finished product [6]. A number of studies [7-9] had been made to improve the ac-cast structures in the last decades, however the problems are not well solved.

Applying electromagnetic field to regulate the as-cast structures of metals and alloys has been researched in steel, aluminum and magnesium industry. However its applied research in copper industry has just started [10]. In this paper, solidification structure change of C19400 copper alloy caused by magnetic field is investigated.

${ }^{a}$ Corresponding author: bmlee@epm.neu.edu.cn 


\section{Experimental procedure}

The experimental set-up is schematically shown in Fig. 1. C19400 alloy was melted in a graphite crucible with dimensions of $\Phi 70 \times 80 \mathrm{~mm}$ using pure copper, pure iron, pure zinc and $\mathrm{Cu}-15 \% \mathrm{P}$ master alloy. The melt was covered by charcoal. After the alloy melt was held at $1250^{\circ} \mathrm{C}$ for $10 \mathrm{~min}$, the crucible with melt in it was quickly placed on the holder. When the melt temperature decreased to $1200{ }^{\circ} \mathrm{C}$ the electromagnetic field was applied. The current frequency was $20 \mathrm{~Hz}$ and the current intensity was $50 \mathrm{~A}$, 75A and 100A respectively. The coil number was 100 .

The ingots were sectioned, polished and etched. Macrostructures were photographed by digital camera and microstructures were observed with optical microscope LEICA-DMR and electron microscope QUANTA-600.

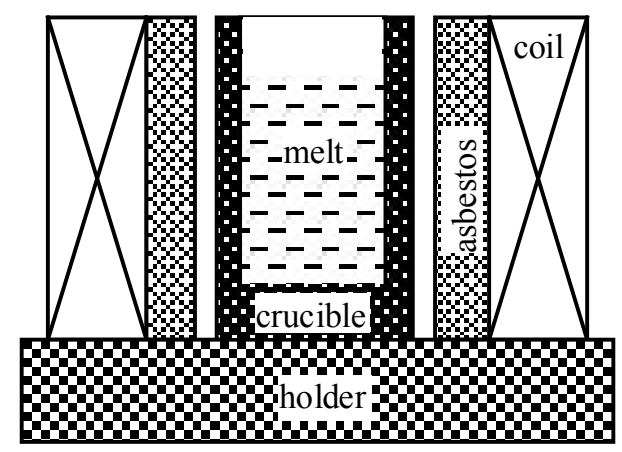

Figure 1. Schematic diagram of experimental set-up.

\section{Results and discussion}
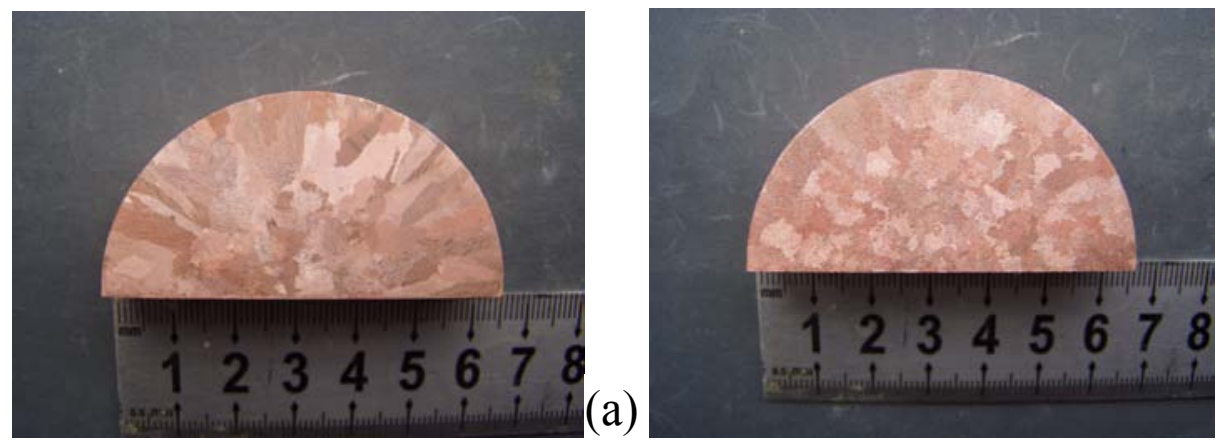

(b)
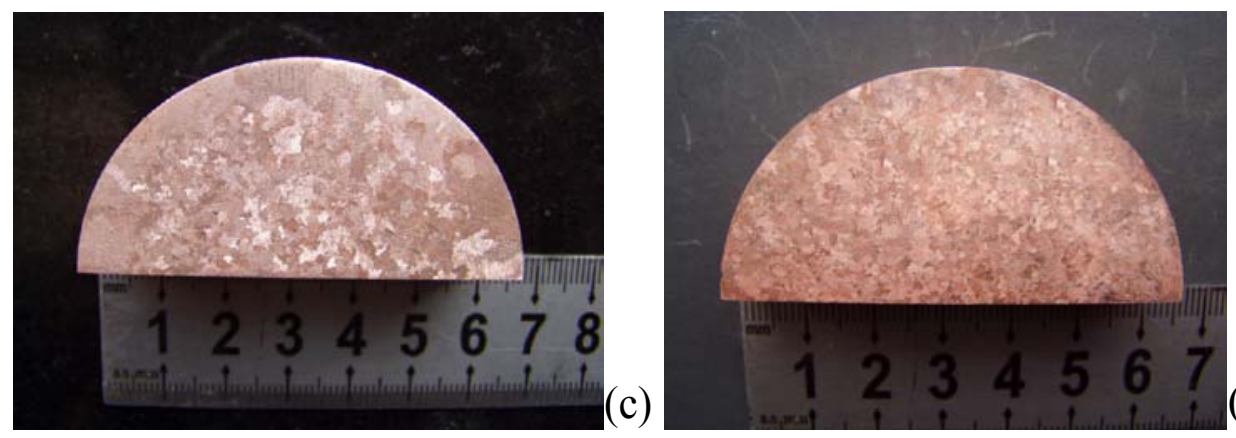

(d)

Figure 2. Macrostructure of as-cast ingots (a) 0A, (b) 50A, (c) 75A, (d) 100A. 
As-cast macrostructure change under different electromagnetic field conditions is shown in Fig. 2. Fig. 2(a) presents the macrostructure of the specimen imposed by the current intensity of 0A. The structure is composed of exterior coarse columnar grains and inner coarse equiaxed grains. In contrast, the exterior coarse columnar grains transform to equiaxed grains and the structure is composed of equiaxed grains when the specimen is subjected to the magnetic fields, as shown in Fig. 2(b). With the increase in current intensity, the grain size is gradually reduced and the structure is composed of uniform and fine equiaxed grains when the current intensity is 100A, as shown in Fig. 2(c, d).

Fig. 3 shows the effect of electromagnetic field on the microstructures of as-cast ingots. Comparing Fig. 3(a) with 3(b-d), it can be found that the morphology of primary crystals and eutactics has been changed remarkably. When current intensity is 0A(Fig. 3(a)), the structure is composed of developed dendrites and eutectics with strip and isolated-island morphology. Applying electromagnetic field during solidification, the developed dendrites gradually degenerate and the amount, width and morphology of eutactics change significantly, as shown in Fig. 3(b-d). When the current intensity is 50A(Fig. 3(b)) the amount of eutactics reduce obviously while the morphology and width of eutactics change a little. When the current intensity is $75 \mathrm{~A}$ (Fig. 3(c)) the isolated-island eutactics increase and the amount of strip eutactics reduce obviously, but the width of eutactics changes a little compared with Fig. 3(b). When the current intensity is $100 \mathrm{~A}($ Fig. 3(d)) the isolated-island eutactics prevail and the strip eutactics disappear basically, the amount of eutactics reduce further and the width narrows obviously.
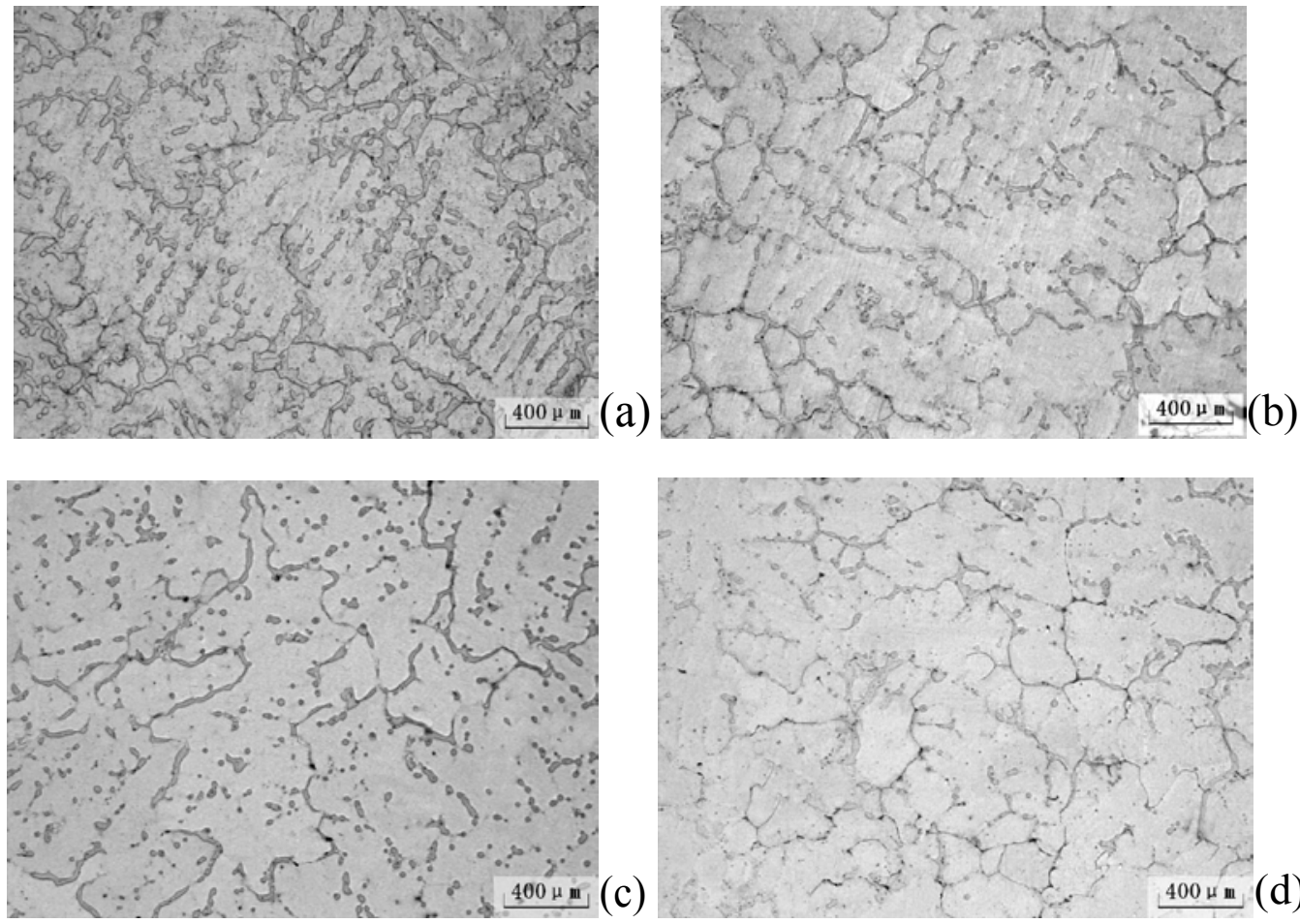

Figure 3. Microstructure of as-cast ingots under different current intensity (a) 0A, (b) 50A, (c) 75A, (d) 100A.

In order to investigate the effect of electromagnetic field on the morphology of $\mathrm{Fe}_{2} \mathrm{P}$ phase of as-cast ingots, the structure is observed by SEM. The results are shown in Fig. 4. It can be seen from Fig. 4(a) that in the absence of electromagnetic field the $\mathrm{Fe}_{2} \mathrm{P}$ phases take coarse irregular shape, while under the effect of electromagnetic field, the morphology of $\mathrm{Fe}_{2} \mathrm{P}$ phase changes from coarse irregular shape to fine dotlike shape, as shown in Fig. 4(b-d). Besides the dimensions of $\mathrm{Fe}_{2} \mathrm{P}$ phases reduce gradually with the increase in current intensity.

Wide strip eutactics and coarse irregular $\mathrm{Fe}_{2} \mathrm{P}$ phase are the origin of crack of C19400 copper alloy semi-continuous ingots, it can be deduced therefore that applying electromagnetic field during C19400 
copper alloy semi-continuous casting can effectively prevent the formation of cracks. In addition, the reduction of eutactics means the improvement of ingot formability, thus favoring the subsequent mechanical working.
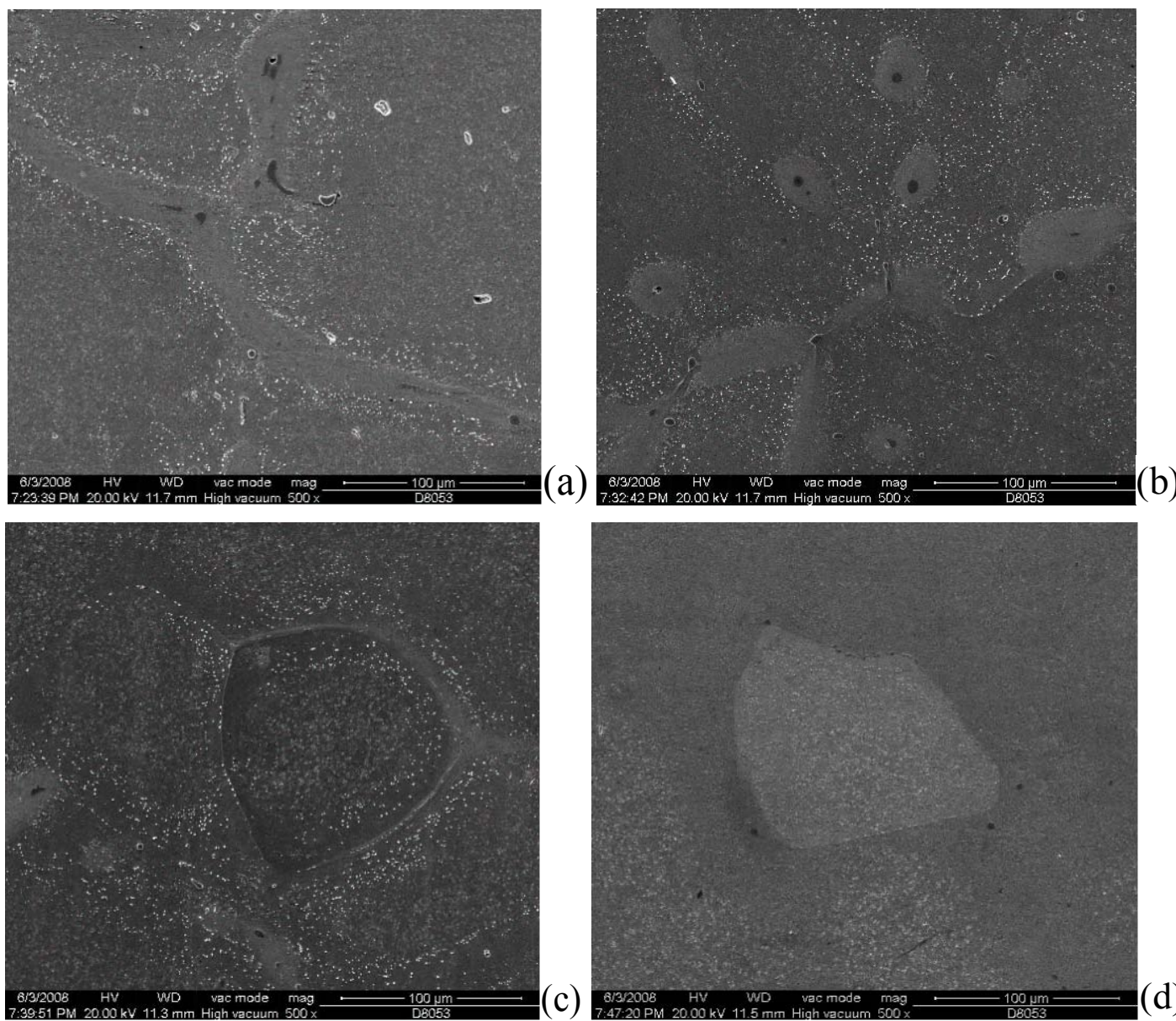

Figure 4. Morphology of $\mathrm{Fe}_{2} \mathrm{P}$ phase under different current intensity (a) 0A, (b) 50A, (c) 75A, (d) 100A.

As-cast structure change of metals and alloys caused by electromagnetic field is mainly owed to the forced bulk melt flow induced by it [11-15]. First, the forced bulk melt flow may cut dendrite arms down, accelerate solute diffusion velocity to remelt dendrite arm roots rapidly and may produce shearing strength at dendrite arm roots, which will induce re-crystal of new nuclei at dendrite arm roots and ultimately fragmentate dendrite arms. Afterward, these fragmentated dendrite arms are taken by the alloy melt flow to other places and act as new nuclei, which will make primary dendrites refined. Second, the strong melt flow can lead to the separating of crystals from mould wall, which can also serve as nucleation sites when carried into the bulk melt by convention. Third, the forced bulk melt flow can increase the heat transfer rate and quickly distribute the latent heat released from the solidification front into the bulk melt, as a result decreasing the temperature gradients in the bulk melt and extending the undercooled region. Small temperature gradients in the bulk melt and large undercooled region inhibit the development of dendrites and favor the formation of equiaxed grains, namely promote columnar-to-equiaxed transition.

The forced bulk melt flow becomes stronger with the increase in current intensity, thus the effect of grain refining and the extent of columnar-to-equiaxed transition become more obvious with the increase in current intensity. 


\section{Conclusions}

Electromagnetic field can promote columnar-to-equiaxed transition. The effect becomes more obvious with the increase in current intensity. When current intensity is $100 \mathrm{~A}$ the structure is composed wholly of uniform and fine equiaxed grains.

Applying electromagnetic field during the solidification of C19400 copper alloy can refine grain, eutactics and $\mathrm{Fe}_{2} \mathrm{P}$ phase.

The morphology of $\mathrm{Fe}_{2} \mathrm{P}$ phase changes gradually from coarse irregular shape to fine dotlike shape with the increase in current intensity.

\section{Acknowledgements}

This research was supported by the National Basic Research Program of China (973 Prophase Research Program) under Grant No. 2009CB626601.

\section{References}

1. H. Q. Li, S. S. Xie and X. J. Mi. Foundry Technology Vol. 27 (2006), P. 1205. (in Chinese)

2. H. J. RYU, H. K. BAIK. J Mater Sci Vol. 35 (2000), P. 3641.

3. S. Suzuki, N. Shibutani. Journal of Alloys and Compounds Vol. 417 (2006), P. 116.

4. Y. Yamamoto, G. Sasaki. Hitachi Cable Review Vol. 59 (2000), P. 65.

5. M. Yamamoto, T. Mizuguchi. Canadian Metallurgical Quarterly Vol. 38 (1999), P. 387.

6. F. Lopez, J. Reyes: J. Mater. Eng. Perform. Vol. 6 (1997), P. 611.

7. D. P. Lu, P. Wang and W. J. Zeng. Materials Science and Engineering Vol. A 421 (2006), P. 254.

8. J. J. Fang. Nonferous Metals Processing Vol. 40 (2011), P.7. (in Chinese)

9. Q. S. Zhong, Y. Z. Yang and X. Z. Cheng. Foundry Vol. 56 (2007), P. 1044.

10. Z. Q. Cao, J. L. Kang and T. J. Li. Functional Materials Vol. 43 (2012), P. 166. (in Chinese)

11. C. Vives. Metall. Trans. Vol. B20 (1989), P. 623.

12. A. RADJAI, K. MIWA and T. NISHIO. Metall. Trans. Vol. A29 (1998), P. 1477.

13. W. J. Boettinger, S. R. Coriell and A. L. Greer. Acta Mater. Vol. 48 (2000) P. 43.

14. H. Conrad. Mater. Sci. Eng. Vol. A287 (2000), P. 205.

15. B. J. Zhang, J. Z. Cui. Acta Metallurgica Sinica Vol. 38 (2002), P. 215. (in Chinese) 